\title{
Parceria universidade e escola no estágio curricular: um processo em constituição
}

\author{
University-school partnership in pre-service teacher: a \\ constitution of the process
}

\section{Le partenariat université et école dans le stage supervisé : un processus en constitution}

\section{Marina Cyrino, Samuel de Souza Neto*}

\section{Resumo}

O presente trabalho concentra-se em discutir o estágio curricular na formação inicial de professores dos anos inicias do ensino fundamental, focalizando a constituição de uma relação de parceria entre universidade e escola. Buscamos como objetivos identificar o compromisso da escola na formação inicial de professores e demonstrar as possibilidades de um processo de construção da parceria entre universidade e escola. A investigação longitudinal (2010-2015) que envolve dados de duas pesquisas (mestrado e doutorado), de natureza qualitativa, ocorreu no curso de Licenciatura em Pedagogia da Unesp-Rio Claro. Contou com a colaboração

MC: Doutora em Educação, e-mail: ma.cyrino@hotmail.com

SSN: Doutor em Educação, e-mail: samuelsn@rc.unesp.br 
de seis escolas e o envolvimento de professores, diretor e coordenadores, bem como a participação da professora supervisora da universidade responsável pelos estágios. A coleta de dados foi realizada em duas etapas: na primeira foram realizadas observações e entrevistas individuais semiestruturadas e; no segundo momento realizamos grupos focais com os participantes. Os dados foram organizados e apresentados em dois eixos temáticos: o compromisso das escolas na formação dos futuros professores e; o processo de constituição de uma parceria. Pudemos perceber o movimento de construção da parceria entre universidade e escola e as necessidades pontuadas por cada uma das instituições. Verificamos que a escola, à sua maneira, recepciona e é aberta aos estagiários, solicitam um trabalho em parceria, mas nem sempre são incluídas intencionalmente no processo. Foi possível perceber que há uma transição entre a parceria de serviço e a parceria de reciprocidade. Sendo assim, com a colaboração dos participantes, criamos dois dispositivos de formação que pudessem incluir a escola e a universidade de maneira formal no acompanhamento dos estagiários. Tais dispositivos contribuem para o processo de profissionalização docente na medida em que possibilita aos atores papéis formais, intencionais, sistematizados e horizontais na formação de seus pares.

Palavras-chave: Formação inicial de professores. Profissionalização docente. Estágio curricular. Licenciatura em Pedagogia.

\section{Abstract}

Current paper analyzes pre-service teacher training in the Education program, focusing the university-school partnership. The aim was to identify the commitment of scholar institution in initial teacher education and; to demonstrate the possibilities of a partnership constitution process. The longitudinal qualitative research (2010-2015), with data of two researches (master and doctorate) took place at Unesp/Rio Claro. We have collaboration of six primary schools, school teachers, a school principal, pedagogical-coordinators of schools and the pre-service Supervisor (university professor). Data collection was performed in two phases that comprised: 1) observation and individuals semi-structured interviews; 2) focus groups. We organized the data in two axes: 1) the school commitment in initial teacher education; 2) the partnership constitution process. We perceived the partnership constitution movement between university and school, as well as the needs of each institution. We verified that the school is open and to student-teaches, request the partnership with university, but they are not formally included in 
the process. Thus, there is a transition between the service partnership and reciprocity partnership. Therefore, we created two formation devices, including school and university formally in student teacher accompaniment process. These devices can contribute for teacher professionalization, because they offer formal, intentional, systematized roles to formation actors.

Keywords: Initial teacher training. Teacher professionalization. Pre-service teacher training. Pedagogy course.

\section{Résumé}

Cet article porte sur le stage dans la formation initiale des enseignants, portant sur la constitution d'une relation de partenariat entre l'université et l'école. Les objectifs sont : identifier l'engagement de l'école dans la formation initiale des enseignants et ; démontrer les possibilités du processus de construction de partenariat entre l'Université et l'école. L'investigation qualitative longitudinale (2010-2015) avec les donnes de deux recherches (Master et Doctorat), a eu lieu dans six écoles. Ils ont participé les enseignants partenaires des écoles, coordinateurs et directeur, bien que le superviseur universitaire de stage. La collecte de donnes a été réalisée en deux étapes: Premièrement, nous avons fait des observations et entrevues individuelles; deuxièmement nous avons réalisé les groupes de discussion. Les donnes ont été organisées en deux axes thématiques : l'engagement de l'école dans la formation des futurs enseignants et; le processus de constitution de partenariat entre lúniversité et l'école. Nous avons vérifié que les écoles reçoivent et ouvrent leurs portes aux stagiaires, mais ni toujours sont impliqué formellement dans le processus du stage. Nous avons aperçu qu'il y aura un mouvement de transition entre le partenariat de service et le partenariat de réciprocité. Ainsi, à l'aide des participants de la recherche, nous avons créé deux dispositifs de formation afin d'impliquer l'école officiellement dans le processus de stage. Ces dispositifs peuvent contribuer pour la professionnalisation des enseignants parce qu'ils permettent aux acteurs un rôle plus formel, intentionnel, systématisé et non hiérarchisé dans la formation des leur pairs.

Mots-clés: Formation initiale des enseignants. Professionnalisation des enseignants. Stage. Formation. Formation initiale des futurs enseignants de l'éducation primaire. 


\section{Introdução ${ }^{1}$}

A formação inicial de professores passou por uma estruturação proveniente do movimento de profissionalização do ensino iniciado no final da década de 80. Surge na América do Norte (Estados Unidos e Canadá) com o intuito de consolidar o ofício docente e torná-lo uma profissão, estruturando-a a partir de sua carreira (HOLMES GROUP, 1986).

Neste processo, pontuou-se que a formação docente deveria ser oferecida em nível superior, possuir conhecimentos específicos e especializados (SHULMAN, 1987), centrada na prática, formando professores autônomos e responsáveis que sejam capazes de refletir e explicitar racionalmente suas práticas (ALTET, 2001).

Assim, se antes as instituições de ensino superior formavam prioritariamente pesquisadores, cientistas e profissionais, após as reformas dos anos 90 e com o movimento de profissionalização do ensino, se responsabilizou pela formação de professores da educação básica, tendo a necessidade de se reestruturar.

Identificando que neste processo há limites, as IES, com um modelo acadêmico de formação (BORGES, 2008), passam por diversos desafios quanto à sua organização curricular, estrutura e adequação para acolher as licenciaturas e suas especificidades: contemplar no currículo uma relação dialógica entre a teoria e a prática, valorizar os profissionais e os espaços de formação profissional e estabelecer uma parceria (de fato) com as instituições escolares.

Neste contexto, a prática ganha destaque nos normativos legais atuais (BRASIL, 2001; 2002), sendo assumida de duas maneiras: prática como componente curricular e estágio curricular supervisionado. Mesmo possuindo elementos próximos e cargas horárias estabelecidas para cada um, estes dois modos de organizar a prática no currículo causou, e ainda causa, certa confusão (DINIZ-PEREIRA, 2011). Assim, os estágios curriculares acabam por assumir a maior parte do momento prático nos cursos de

1 Agência Financiadora: FAPESP. 
licenciatura, sendo a partir deste que os estudantes passam a ter contato com a realidade escolar sob a ótica profissional.

Apesar destes entraves, consideramos que para os estágios serem de fato significativos enquanto uma experiência e vivência inicial na profissão, é imprescindível que haja uma relação positiva e horizontal entre as instituições envolvidas neste processo: universidade e escola.

Em diversos países como França e Canadá (Quebec) encontramos políticas públicas que subsidiam tal relação na forma de parcerias ou trabalhos colaborativos entre as duas instituições. Em outros contextos, como no Brasil, a relação é fragilizada, necessitando ser conquistada aos poucos, geralmente na camaradagem e de maneira independente (por vezes solitária).

A constituição de parcerias ou trabalhos em colaboração entre IES e escolas é apoiada pelo movimento de profissionalização do ensino (HOLMES GROUP, 1995), o qual valoriza e orienta que a formação para a docência seja voltada à atividade profissional estabelecendo elos mais fortes com o meio profissional, no caso, a escola (BOURDONCLE, 2000). Portanto, a colaboração entre ambas é um dos enfoques em destaque e mais valorizado para melhorar e profissionalizar a profissão docente (MICHAUD, 1999).

Para além da ideia de colaboração e parceria, no processo de construção da profissão docente é importante que os professores possam formar seus futuros pares, pois "a formação dos docentes é uma responsabilidade coletiva de toda a profissão docente, assim como das autoridades escolares: estabelecimentos, comissões escolares, etc." (TARDIF, 2008, p. 25).

No entanto, na realidade brasileira enfrentamos desafios que muitas vezes dificultam o desenvolvimento desse processo, como: as condições de trabalho dos professores universitários responsáveis pelo estágio para que de fato realizem a supervisão; condições objetivas dos professores e da escola para recepcionar, orientar e formar os estagiários; o reconhecimento pela escola e pela IES de seu real compromisso e papel formativo; as diversas concepções de estágio que estão presentes em um mesmo contexto; a pouca real importância que é dada ao estágio e as 
práticas nas IES; ausência de investimento em programas nacionais ou estaduais de estágios para as licenciaturas o qual possa favorecer as parcerias, oferecer formação aos professores da escola e estreitar os vínculos entre os formadores.

Em meio a tantos desafios, há cursos de licenciatura que promovem experiências a fim de superar este quadro, mesmo com todas as limitações. Para nosso estudo, citamos a Unesp/Rio Claro, curso de Pedagogia, onde há uma iniciativa da professora supervisora em estabelecer um vínculo formalizado com as escolas e professores que recebem seus estagiários. A proximidade desta universidade com a rede municipal de ensino nos permitiu desenvolver investigações acerca do compromisso da escola na formação inicial de professores, das relações de parceria estabelecidas, bem como possibilitou um olhar para pensar em um acompanhamento compartilhado de estagiários.

Sendo assim, o presente trabalho tratará diretamente dos dois primeiros pontos, objetivando identificar o compromisso da escola na formação inicial de professores e demonstrar as possibilidades de um processo de construção da parceria universidade e escola.

Por meio de um estudo qualitativo longitudinal dividido em duas etapas (mestrado e doutorado), foram realizadas entrevistas, observações, grupos focais e acompanhamento dos estágios em seis escolas do município e na universidade. Participaram diretor, coordenadoras e professoras de seis escolas, professora universitária responsável pelos estágios (supervisora) e duas responsáveis da Secretaria Municipal de Educação.

\section{Desenvolvimento}

O presente tópico está organizado em três itens que correspondem ao Referencial Teórico, no qual à Metodologia, aos Resultados e Discussão. 


\section{Referencial Teórico}

A relação entre teoria e prática é tema debatido há algum tempo nas discussões sobre formação de professores. Geralmente encontramos tal temática diretamente relacionada ao estágio curricular supervisionado, momento em que a maioria dos licenciandos tem o maior contato com a realidade profissional e confrontam com as teorias advindas das IES.

Historicamente, a relação entre escola e universidade tem sido conflituosa (PIMENTA; LIMA, 2004), pois há a ideia de que a teoria, pautada em uma realidade discursiva, não é aplicável a realidade prática da escola. Assim,

a prática pela prática e o emprego de instrumentais isolados podem trazer a ilusão de que há uma prática sem teoria, ou uma teoria desvinculada da prática, razão porque é comum ouvir-se da parte dos professores: na minha prática, a teoria é outra (LIMA, 2002, p. 249).

Para além da relação teoria e prática, escola e IES tem se distanciado, pois cada uma possui uma cultura específica, as políticas públicas pouco tem apoiado relações de colaboração entre ambas as instituições na formação de professores, as condições objetivas oferecidas a estes dois lugares para a formação docente são escassas, o modelo de formação que predomina atualmente é o acadêmico em contraposição com o modelo profissional (BORGES, 2008) e acordos interinstitucionais, quando existentes, são na maioria das vezes burocráticos.

Por estes e outros motivos, as IES brasileiras "não costumam manter um trabalho articulado com as escolas de educação básica que recebem seus estagiários" (SARTI, 2009, p. 135), estas, por sua vez, geralmente têm o papel somente de receber os estagiários, abrir as portas e oferecer-lhes a estrutura física.

$\mathrm{Na}$ contramão deste episódio, a partir de estudos realizados (CYRINO; SOUZA NETO, 2014), foi possível encontrar inúmeros trabalhos em âmbito nacional e internacional que apresentaram experiências de aproximação, colaboração e parceria entre escola e universidade ou instituição formadora. 
Foi possível observar que em outros países como França e Canadá há uma legislação preocupada sistematicamente com a formação de futuros professores, que possibilita e oferece subsídios a relação de colaboração e parceria entre a IES e a escola. Ambos os países possuem uma concepção mais clara e formalizada sobre a escola enquanto um espaço de formação, bem como sobre a função formal do professor da escola que recebe estagiários, os chamados formadores.

No Brasil, mesmo com os desafios encontrados e os tímidos avanços de nossos normativos legais relacionados ao estágio e à parceria (BRASIL, 2015; 2008; 2001), as universidades tem se esforçado para estabelecerem vínculos de parceria com as escolas.

Este processo é uma prática que vem sendo discutida "tanto nos órgãos da administração pública, como entre o professorado e no meio acadêmico, parceria é usada como uma possibilidade emergente de colaboração, cooperação, partilha de compromissos e responsabilidades" (FOERSTE, 2004, p. 2).

Assim, a parceria não é somente uma assinatura de um contrato de estágio ou de um convênio entre Secretarias de Educação e Instituições formadoras, mas é considerada como uma relação de colaboração, na qual as partes apresentam uma visão compartilhada, seguem um objetivo comum e cada parte tem clareza de seus papéis (GERVAIS, 2008).

A parceria implica ainda uma concepção de trabalho em equipe, de uma relação de poder compartilhada, valores comuns, tomada de decisão em conjunto, papéis e responsabilidades claramente definidos. Assim,

As vozes do indivíduo e do grupo são compreendidas e levadas em consideração. É uma parceria na qual os professores e outras partes interessadas estão ativamente engajados no processo de negociação e no seu desfecho aos resultados e no qual se evita as relações de poder inerentes aos modelos tradicionais (DAY, 2001, p. 48).

Gervais (2008) tem estudado profundamente o conceito e as práticas de parceria e aponta que pode ser encontrada em duas formas: de serviço e de reciprocidade. O tipo mais comum de se encontrar no Brasil 
é a de serviço, pois nesta relação de parceria o objetivo e seu desenvolvimento é realizado por um só ator, no caso a universidade, sendo esta também a responsável por verificar se os objetivos foram cumpridos e solicitar as respostas dos seus pares.

Portanto, comprometer-se com a formação de um estudante que não faz parte formalmente de suas responsabilidades burocráticas é algo muito complexo para a escola brasileira. Na legislação atual relacionada aos estágios (BRASIL, 2008) é possível observar que a escola não apresenta uma função formal no que tange aos estagiários. Cabe a ela a abertura do espaço, recepção e apoio aos estagiários.

Mas, sabemos que na maior parte das escolas que apresentam a prática de receber estagiários, o estágio faz parte de suas rotinas. Porém, mesmo com a compreensão de que os estágios fazem parte da rotina, estes não são uma necessidade imediata da escola. Ou seja, na medida em que os estudantes universitários se fazem presentes no ambiente escolar, é que se pode olhar a maneira como contribuem.

De qualquer forma, destacamos a possibilidade de este espaço assumir um compromisso formal com a preparação de seus futuros profissionais. Compreendemos que este compromisso é uma ação moral (CONTRERAS, 2002, p. 79), desta forma, não pode ser algo imposto, uma regra, mas deve partir dos envolvidos no processo. O referido autor aponta que o compromisso moral é exercido pelos docentes a partir de uma autonomia e não da obediência a uma regra. É exatamente a ideia de parceria compreendida neste estudo.

Mas de que forma podemos exercitar este compromisso? Quais são os elementos necessários para esta prática? É possível pensar neste assunto?

A ideia que coloca-se aqui segue a perspectiva de um modelo de formação profissional, ou seja, uma formação em que "passa a ser 'centrada na escola' e que os processos formativos passam a ser considerados como processos de intervenção nas organizações escolares" (CANÁRIO, 2000, p. 12). Um modelo no qual os estágios estão no centro do currículo e contam com as relações de parceria formalmente estabelecidas com as 
escolas, na qual cada ator tem um papel definido, com objetivos claros e estabelecidos por ambas as partes, visando formar professores a partir do contexto da atividade profissional e que sejam capazes de refletir sistematicamente sobre suas práticas, explicitando intencionalmente seus saberes profissionais (TARDIF, 2008).

\section{Metodologia}

Trata-se de um estudo qualitativo que teve início em 2010, perdurando até 2015. A investigação longitudinal ocorreu em duas etapas, sendo que na primeira apresentou um caráter descritivo e exploratório e na segunda etapa nos pautamos na perspectiva construtivo-colaborativa (COLE; KNOWLES, 1993), a qual envolve novas maneiras de se constituir a parceria entre universidade e escola, de modo que os professores da escola sejam incluídos no processo e não apenas participantes.

$\mathrm{Na}$ primeira etapa, tomando como base os dados advindos de nossa pesquisa de mestrado, utilizamos como técnicas para coleta de dados a observação não participante e a entrevista individual semiestruturada (LÜDKE; ANDRÉ, 1986). Realizamos a observação em três espaços diferentes: estágios realizados por estudantes em seis escolas (A; B; F; G; K; L); aulas da disciplina teórica na universidade; curso de extensão elaborado pela professora universitária e oferecido aos professores da escola que recebem estagiários. O tempo destinado à observação foi de três meses (abril a junho de 2011), totalizando 160 horas nas escolas, 28 horas de acompanhamento das aulas da universidade e 14 horas no curso de extensão.

As entrevistas individuais semiestruturadas ocorreram com 16 participantes, sendo seis professoras-colaboradoras ${ }^{2}$ (PC); seis coordenadoras (C); uma vice-diretora (VD); uma professora universitária responsável pelo estágio e; duas pessoas da Secretaria Municipal de Educação responsáveis pelo estágio (SME-1 e SME-2).

2 Professoras que recebem estagiários nas escolas. 
Na segunda etapa da coleta de dados, iniciada em 2013, incluímos resultados advindos do doutorado, utilizando como técnicas a observação participante da disciplina de acompanhamento do estágio oferecida na universidade; realização de seis grupos focais, os quais participaram um total de doze professoras (P); três coordenadoras pedagógicas $(C)$ e um diretor (D), totalizando 16 participantes. A professora supervisora da universidade também participou desta etapa da pesquisa como colaboradora ativa no processo de construção dos resultados. Para a análise dos dados utilizamos elementos da análise de conteúdo (ANDRÉ, 1983), organizando os resultados em eixos temáticos, os quais nos permitiu um olhar detalhado e ao mesmo tempo ampliado sobre o estágio.

\section{Resultados e Discussões}

Neste subitem, realizamos a apresentação do contexto da pesquisa e a organização de nossos resultados que se pauta em dois eixos principais: o compromisso informal das escolas na formação dos futuros professores; o processo de constituição de uma parceria. A discussão e apresentação dos dados são apresentadas em concomitância.

\section{Contexto}

Os estágios no curso de Licenciatura em Pedagogia da UnespRio Claro estão divididos em: Educação Infantil, Ensino Fundamental I e Gestão Escolar. Cada estágio é de responsabilidade de uma professora universitária e cabe à cada uma organizar, estruturar e propor o estágio como preferirem, seguindo as orientações do Projeto Pedagógico do curso.

Nossa investigação acompanhou o estágio de Ensino Fundamental I, dividido em duas disciplinas: Planejamento, Acompanhamento e Noções Teóricas de Prática de Ensino nos Anos Iniciais do Ensino Fundamental e Estágio Supervisionado de Prática de Ensino nos Anos Iniciais do Ensino Fundamental. Elas ocorrem no quinto semestre do curso ( $3^{\circ}$ ano) de forma concomitante. 
A primeira disciplina corresponde às aulas teóricas na universidade e a segunda relaciona-se ao estágio realizado nas escolas, com 105 horas de prática. A proposta é que os estagiários desenvolvam um projeto pedagógico juntamente com o professor da escola que o acompanha, ou seja, constituam um trabalho em parceria.

Esta proposta tem se desenvolvido por meio da chamada Parceria Intergeracional (SARTI, 2009; 2013), com início desde 2006 e se constituindo até os dias atuais, a proposta visa estabelecer vínculos fortalecidos com os professores que, sendo convidados a participar da proposta, recebem os estagiários nas escolas. Estes docentes são reconhecidos como professores experientes e iniciantes de uma nova geração de professores

algo que lhes possibilita vivenciar novas aprendizagens, ao mesmo tempo que sentimentos de valorização de seus saberes e práticas profissionais. Por meio dessa proposta de parceria entre diferentes gerações docentes, busca-se investir no desenvolvimento de uma dimensão mais colaborativa no seio da cultura do magistério (SARTI, 2009, p. 134).

No início do projeto, a professora supervisora ofereceu cursos de extensão aos docentes, a fim de discutir sobre o estágio e oferecer-lhes uma formação que pudesse sensibilizá-los para o estágio e para a formação dos futuros professores, sendo que "a cada ano, o curso focaliza aspectos diferentes da aprendizagem profissional docente e busca enfatizar a importância do papel que os professores experientes desempenham nessa formação" (SARTI, 2013, p. 86).

A proposta foi se constituindo e a cada ano a Supervisora (S) fazia uma reflexão identificando as lacunas, os ganhos e o que podia ser mudado, como relata em entrevista individual: "a partir do momento que o estágio começou a acontecer, eu pude amadurecer um pouco essa ideia”.

Assim, de uma parceria direta com os professores, a proposta passou a ganhar corpo e expandiu para o espaço escolar. A supervisora percebeu que "a escola poderia sim assumir uma responsabilidade maior 
nisto. Então precisava que a escola também percebesse o projeto dentro dela, [...] que isso fosse mais forte" (Supervisora).

Atualmente são 6 escolas fixas que recebem os estagiários, e há uma frequência de certos professores aceitarem receber estagiários todos os anos, criando-se uma rede de escolas e de pessoas que aderem a proposta e aos poucos vão compreendendo seu papel neste processo. Há onze anos a Supervisora vem ganhando espaço nas escolas e na rede municipal, por meio dos resultados de seu próprio trabalho e com a parceria da Secretaria Municipal de Educação.

\section{O compromisso informal das escolas na formação dos futuros professores}

Nas políticas públicas atuais encontramos que o estágio deve ocorrer em parceria com a escola. No entanto, o que se encontra comumente é a escola recebendo estagiários e assinando fichas, ficando sob a responsabilidade da universidade a orientação das práticas. Com isso, a escola permanece como coadjuvante na formação de seus futuros professores. Porém, esta não é uma regra, haja vista a própria proposta de estágio aqui investigada, dentre outras em diversos estados brasileiros.

Na primeira etapa da pesquisa de campo, na qual realizamos entrevistas e observações individuais com os participantes, vimos que estas cumprem com seu papel de receber estagiários, ceder o espaço, encaminhar os estudantes aos professores responsáveis pelas classes, apoiar os estagiários em excursões e providenciar os materiais necessários para a realização do estágio.

Em algumas escolas, os estagiários recebem um crachá identificando-os como alguém que tem uma função no ambiente escolar. Em outras possuem um livro para registrar sua entrada e saída na escola, assim como preenchem uma avaliação de seu período de estágio na escola.

E mesmo que cada escola tenha lidado com os estagiários à sua maneira, todas apresentaram algo em comum: "os estagiários tiveram uma identidade um pouco mais definida na escola, [...] passaram a ser vistos 
como estagiários da escola [...], me parece que a escola se apropriou dos estagiários como estagiários da escola, isto é magnífico" (Supervisora).

Deste modo, as coordenadoras reconhecem que a escola faz parte desta formação inicial do professor, os estágios passam a ser reconhecidos como parte da rotina da escola, de modo que o estagiário não é considerado como um "peso" que a escola deve "carregar", pelo contrário: "nós não vemos o estágio como mais um momento, mas a gente vê o estágio como sendo do cotidiano da escola" (Vice-Diretora - Escola F).

A partir deste reconhecimento, algumas coordenadoras também apontam que se a escola não recepcionar este estagiário "Não adianta depois o coordenador reclamar de que a faculdade, de que a universidade, não dá subsídio. Então assim, a escola tem esse papel importante, mas como eu já disse, depende de todos (Coordenadora - Escola K).

Compreendem, portanto, que não é só na universidade que ocorre a formação do professor, mas um trabalho coletivo com a escola pode auxiliar neste processo. Por outro lado, é fato que os estágios não são uma necessidade imediata da escola, pois "a universidade é que tem a responsabilidade de propor o estágio, [...] e tomara que seja sempre com muita relação com a escola (Supervisora).

Com as breves constatações aqui apresentadas, é possível considerar que a escola teria um compromisso com a formação de licenciados? Identificamos que as escolas, mesmo que informalmente e sem intencionalidade, assumem de alguma maneira certo compromisso com a formação, pois quando decidem receber os estagiários os inserem nas rotinas escolares, possibilitando-os vivenciar e experienciar a atividade docente.

Pudemos perceber que tanto os coordenadores, professores, supervisora e estagiários sentiram um apoio no desenvolvimento dos estágios. Entretanto, por conta das inúmeras tarefas e atividades da instituição escolar, o acompanhamento das práticas é algo que ainda não ocorre, por conta da demanda de estagiários e de uma estrutura sistematizada. 


\section{O processo de constituição de uma parceria}

A partir do contexto apresentado e dos relatos dos participantes sobre o compromisso informal assumido pela escola, passamos a apresentar e explorar a constituição da relação de parceria ou de colaboração entre os agentes escolares e da universidade.

No tópico anterior, pudemos observar que há um esforço da universidade e da escola em estabelecerem que o estágio só ocorre se houver a disposição e certo compromisso assumido de ambas as partes (CYRINO, 2012; 2016). No que diz respeito à instituição escolar, observamos um ensaio na compreensão do estágio e do futuro professor como alguém em formação e que voltará ao ambiente escolar como profissional.

Avançando nestes aspectos, na segunda etapa da pesquisa os participantes apontam nos grupos focais para a questão da parceria, citando a colaboração, o diálogo e a relação universidade e escolas como constituintes deste processo.

Na Escola A, a ideia do estágio como de fato uma parceria é relatada de forma clara:

P1-A⿱3 : bom, vejo o estágio como uma parceria mesmo. O estagiário deveria vir com a orientação de ter parceria com o professor. E nós professores transmitimos nossa experiência, é uma troca de experiências, o estagiário também traz coisas novas para nós.

P2-A: sim, mas a parceria tem que ocorrer dos dois lados, não pode vir de uma pessoa só. Depende da outra parte também. Se o estagiário não entender a parceria, não funciona (Grupo Focal - Escola A).

Neste itinerário, no Grupo Focal da Escola F, foi apontado que o diálogo existe, porém deve ser formalizado.

3 Professora 1 da Escola A. 
P2-F: esse diálogo maior, entendeu? Porque se não, fica muito aquela coisa: 'a universidade lá, a escola aqui, [...] e a gente não entra em um diálogo com aquela escola... e ai a gente não transforma essa escola num espaço de formação. [...] ela é um espaço de formação, mas a própria universidade talvez não legitima isso como espaço de formação, e ela tem que ser legitimada [...]. Ela até fala, nas teorias eles vão falar: 'a escola é espaço de formação', mas assim, vamos tornar isso sólido.

Segundo os relatos dos participantes nos Grupos Focais, as escolas não encontram impasses em receber e orientar estagiários, pois muitas vezes este estudante agrega no trabalho do docente e colabora com a escola. No entanto, foi apontado que a organização e o planejamento são aspectos fundamentais para que o trabalho aconteça da melhor maneira. Outro ponto discutido nos grupos foi sobre até onde é papel da universidade na orientação dos estagiários e em que momento a escola pode assumir o processo de formação.

Assim, para que escola e professores tenham a possibilidade de se envolver na formação de futuros professores, é importante que nos cursos de licenciatura sejam considerados alguns aspectos: tomar o estágio como um elemento central da formação nos Projetos Políticos Pedagógicos dos cursos; elaborar em parceria com as escolas uma proposta de estágio com um objetivo comum traçado de modo que todos os envolvidos compreendam seus papéis e o que está em desenvolvimento.

É necessário, portanto, que haja um diálogo, uma colaboração entre ambas as instituições, considerando os saberes como complementares e não contrapostos. Isso envolve "o empenho mútuo dos participantes", pois a relação de colaboração não está pautada na hierarquia, "mas uma relação entre pessoas que saibam ouvir, compartilhar ideias e trabalhar juntas" (SOUZA NETO, et al., 2012, p. 3). 


\section{Considerações finais}

No trabalho proposto, nossa intenção foi identificar o compromisso da escola na formação inicial de professores e demonstrar as possibilidades de um processo de construção da parceria universidade e escola. Considerando estes dois aspectos, pudemos perceber as escolas mais abertas à universidade, e esta, por sua vez, valorizando as experiências contidas na realidade profissional dos professores.

Vimos na literatura e nos resultados apresentados que a parceria só se constitui a partir de um compromisso assumido por ambas as partes envolvidas no processo de estágio. Assim, a universidade aponta a importância da participação e do envolvimento da escola no processo de formação inicial. Aos poucos, os professores e coordenadores das escolas passam a compreender que eles também possuem um papel específico neste processo.

Mas sinalizar a colaboração e a importância da parceria não basta. A formalização e sistematização destas práticas devem ser exercitadas. Por isso, pensando nestes aspectos, nossa pesquisa tem avançado no sentido de construir com a escola alguns dispositivos de formação e de acompanhamento de estagiários (CYRINO, 2016).

É uma proposta que visa inserir intencionalmente e de maneira sistematizada a escola na formação de estagiários. Portanto, valoriza os aspectos teóricos e reflexivos, bem como os aspectos da experiência e realidade profissional. Constitui-se então em um "movimento de aproximação de duas instituições de ensino, cada uma trazendo valores, objetivos imediatos, cultura e relações de poder diferentes, com o objetivo de realizarem um trabalho comum: a formação de professores" (LIMA, 2008, p. 198).

Assim, consideramos os elementos pontuados pelos participantes nos Grupos Focais, e juntamente com a supervisora de estágio, elaboramos e organizamos dois dispositivos: um voltado aos estagiários com diversas etapas para acompanharem o próprio percurso e exercitarem a reflexão sobre a prática e; outro composto de três roteiros para os 
professores acompanharem os estagiários durante todo o processo de estágio na escola (CYRINO; SOUZA NETO, 2015).

Ambos os dispositivos seguem uma lógica temporal do estágio e visam oferecer um papel mais formalizado ao professor da escola, proporcionando ao estagiário a possibilidade de sistematizar a experiência de estágio e receber um feedback do professor da escola, para que assim, possam exercitar uma reflexão sobre sua prática.

$O$ exercício de inserir escola e universidade em um mesmo processo tem sido uma atividade de criar vínculos, sem hierarquizar nossa posição, mas construir uma relação de igualdade, caminhando na transição de uma parceria de serviço para uma parceria de reciprocidade (GERVAIS, 2008). É uma tarefa difícil por todo o contexto histórico que envolve ambas as instituições. Mas é um caminho que segue a perspectiva da profissionalização do ensino, a partir do momento em que se oferecem aos professores papéis horizontais para formar seus futuros colegas de trabalho, valorizando seus saberes, suas práticas e experiências de ensino como constituintes de novas identidades docentes.

\section{Referências}

ALTET, M. As competências do professor profissional: entre conhecimentos, esquemas de ação e adaptação, saber analisar. In: PAQUAY, L.; PERRENOUD, P.; ALTET, M.; CHARLIER, É. (Orgs.). Formando professores profissionais. Quais estratégias? Quais competências? 2. ed. Porto Alegre: Artmed, 2001. p. 23-35.

ANDRÉ, M. E. D. A. Texto, Contexto e Significados: algumas questões na análise de dados qualitativos. Cadernos de Pesquisa, São Paulo, mai. 1983.

BORGES, C. A formação docente em Educação Física em Quebec: saberes espaços, culturas e agentes. In: ENCONTRO NACIONAL DE DIDÁTICA E PRÁTICA DE ENSINO, 14., 2008. Porto Alegre. Anais... Porto Alegre: Pontifícia Universidade Católica de Porto Alegre, 2008. 1 CD-ROM. 
BOURDONCLE, R. Autour des mots «Professionalisation, Formes et Dispositifs». Recherche et Formation, n. 35, p. 117-132, 2000.

BRASIL. Conselho Nacional de Educação. Parecer CNE/CP nº 9/2001, 8 maio, 2001. Diário Oficial [da] República Federativa do Brasil, Poder Executivo, Brasília, DF, 8 de maio, 2001. Seção 1, p. 131. Disponível em: <http://portal.mec.gov.br/ cne/arquivos/pdf/009.pdf >. Acesso em: 7 out. 2009.

BRASIL. Conselho Nacional de Educação. Resolução CNE/CP 1/2002 18 de fevereiro de 2002. Institui Diretrizes Curriculares Nacionais para a Formação de Professores da Educação Básica, em nível superior, curso de licenciatura, de graduação plena. Diário Oficial [da] República Federativa do Brasil, Poder Executivo, Brasília, DF, 9 abr. 2002a. Seção 1.

BRASIL. Presidência da República/Casa Civil. Lei $n^{0}$. 11.788, de 25 de setembro de 2008. Brasília: Subchefia para Assuntos Jurídicos, 2008.

BRASIL. Conselho Nacional de Educação. Conselho Pleno. Resolução $n^{\circ} 2$, de $^{\circ}{ }^{\circ}$ de julho de 2015. Define as Diretrizes Curriculares Nacionais para a formação inicial em nível superior (cursos de licenciatura, cursos de formação pedagógica para graduados e cursos de segunda licenciatura) e para a formação continuada, 2015.

CANÁRIO, R. A prática profissional na formação de professores. Inafop. Formação profissional de professores no ensino superior. Universidade de Aveiro, 2000. Disponível em: <http://www.fe.unicamp.br/falaoutraescola/resumos-palestrantes/RuiCanario.pdf >. Acesso em: 23 abr. 2012.

COLE, A.; KNOWLES, J. G. Teacher development partnership research: a focus on methods and issues. American Educational Research Journal, v. 30, n. 3, p. 473495, 1993.

CONTRERAS, J. A Autonomia de professores. 1 ed. São Paulo: Cortez, 2002. 
CYRINO, M.; SOUZA NETO, S. de. O acompanhamento de estagiários de pedagogia na escola: análise e reflexão das práticas de ensino 2015. Trabalho apresentado no GT08 - Formação de Professores. Anais da 37a Reunião Científica da ANPEd. Florianópolis, Outubro de 2015. ISSN: 2447-2808.. Disponível em: 〈http://www.anped.org.br/sites/default/files/trabalho-gt08-4594.pdf〉. Acesso em: 12 dez. 2015.

CYRINO, M.; SOUZA NETO, S. de. O estágio curricular supervisionado na experiência brasileira e internacional. Revista Educação em Questão, Natal, v. 48, n. 34, p. 86-115, jan./abr. 2014. Disponível em: <http://www.periodicos.ufrn.br/ educacaoemquestao/article/view/5731>. Acesso em : 17 mar. 2014.

CYRINO, M. Formação inicial de professores: o compromisso do professor-colaborador e da instituição escolar no processo de estágio supervisionado. 2012. 233f. Dissertação (Mestrado em Educação)-Programa de Pós-Graduação em Educação, Universidade Estadual Paulista, Rio Claro, 2012.

CYRINO, M. Do acolhimento ao acompanhamento compartilhado: A construção colaborativa de uma proposta para o estágio curricular no curso de pedagogia. 2016. Tese (Doutorado). 345f. Programa de Pós-Graduação em Educação. Unesp - Rio Claro. 2016. Disponível em: 〈http://hdl.handle.net/11449/137997〉.

DAY, C. F., Développement professionnel et pratique réflexive : finalités, processus et partenariats. Carrefours de l'éducation, v. 2 n. 12, p. 40-54, 2001.

DINIZ-PEREIRA, J. E. A prática como componente curricular na formação de professores. Educação, Santa Maria, v. 36, n. 2, p. 203-218, maio/ago. 2011.

FOERSTE, E. Parceria na formação de professores. Revista Iberoamericana de Educación, sección De los lectores, 25/04/2004, p. 1-13, 2004. Disponível em: http://www.rieoei.org/deloslectores/554Foerste.PDF. Acesso em: 12 ago. 2010.

GERVAIS, C. Pour une formation des stagiaires en concertation: le rôle des superviseurs. In: BOUTET, M.; PHARAND, J. L'Accompagnement concerté des stagiaires en enseignement. Québec: Presses de l'Université du Québec, 2008. p. 91-108. 
HOLMES GROUP. Tomorrow's teachers: A report of the Holmes Group. East Lansing. Michigan: Holmes Group, 1986.

HOLMES GROUP. Tomorrow's schools of education. East Lansing, MI: The Holmes Group, 1995.

LIMA, M. S. L. Práticas de Estágio Supervisionado em formação continuada. In: ROSA, D. E. G.; SOUZA, V. C. (org.). Didática e práticas de ensino: interfaces com diferentes saberes e lugares formativos. Rio de Janeiro: DP\&A, 2002. p. 243-253.

LIMA, M. S. L. Reflexões sobre o estágio/prática de ensino na formação de professores. Rev. Diálogo Educ., Curitiba, v. 8, n. 23, p. 195-205, jan./abr. 2008.

LÜDKE, M.; ANDRÉ, M. Pesquisa em Educação: Abordagens Qualitativas. São Paulo: EPU, 1986.

MICHAUD, C. Interaction des savoirs et des pouvoirs en formation des enseignants : une analyse de discours partenariaux. Nouveaux c@hiers de la recherche en éducation, v. 6, n. 3, p. 421-440, 1999. Disponível em: <http://id.erudit.org/ iderudit/1016978ar>. Acesso em: 19 jul. 2014.

PIMENTA, S. G.; LIMA, M. S. L. Estágio e Docência. São Paulo: Cortez, 2004.

SARTI, F. M. Parceria intergeracional e formação docente. Educ. Rev., Belo Horizonte, v. 25, n. 2, ago. 2009. Disponível em: <http://educa.fcc.org.br/scielo.php?script=sci_arttext\&pid=S0102-6982009000200006\&lng=es\&nrm=iso $\geq$. Acesso em: 24 jan. 2010.

SARTI, F. M. Relações intergeracionais e alternância na formação docente: considerações a partir de uma proposta de estágio supervisionado. Cadernos de Educação, Pelotas, n. 46, p. 83-99 set./dez. 2013. Disponível em: <http://periodicos.ufpel.edu.br/ojs2/index.php/caduc/article/view/4174>. Acesso em: 12 abr. 2015. 
SOUZA NETO, S.; BENITES, L. C.; IAOCHITE, R. T. A colaboração no estágio supervisionado como mediadora da relação universidade-escola e entre supervisor, estagiário e professor-colaborador. In: Congresso Internacional de Educação Física - O ensino da educação física nos ensinos básico e secundário: Educação e Formação - tendências atuais. 1. Maia, Portugal. Anais... Maia: Instituto Superior de Maia (ISMAI), 2012.

SHULMAN, L. Knowledge and teaching: foundations of a new reform. Harvard Educational Review, Cambridge, v. 57, n. 1, p. 1-22, 1987.

TARDIF, M. Princípios para guiar a aplicação dos programas de formação inicial para o ensino. In: ENCONTRO NACIONAL DE DIDÁTICA E PRÁTICA DE ENSINO (ENDIPE) 14., 2008. Porto Alegre. Anais... Porto Alegre: Pontifícia Universidade Católica de Porto Alegre, 2008. 1 CD-ROM.

Recebido: 30/11/2015

Received: 11/30/2015

Aprovado: 25/05/2017

Approved: 05/25/2017 